\title{
The Influence of Dietary Cholesterol and Fat on the Homeostasis of Cholesterol Metabolism in Early Life in the Rat
}

\author{
SYII) M. NASILLM. ${ }^{(B *}$ MUSHTAQ A. KHAN. MAR('S. JACOBSON, PADMANABHAN P. NAIR, ANI) \\ FELIX P. HLALD \\ Division of Adolescent Medicine and Department of Pediatrics. Liniversity of Maryland School of Medicine. Baltimore. \\ Maryland. USA
}

\begin{abstract}
Summary
Evidence has accumulated suggesting that exposure to dietary cholesterol during early developmental stages activates biochemical mechanisms that regulate cholesterol homeostasis in adult life. Pregnant Sprague-Dawley rats were fed control or $1 \%$ cholesterol |high cholesterol-high fat (HC-HF)| liquid diet during gestation, and with the same diet, offsprings were challenged at maturity-3-Hydroxy-3-methylglutaryl-coenzyme A reductase activity deckned by $76 \%$, and cholesterol $7 \alpha$-hydroxylase activity increased by $200 \%$. Microsomal and serum cholesterol accumulation also increased significantly. Exposure to HC-HF diet during suckling and continued exposure with the same diet postweaning resulted in 52\% decline in 3-hydroxy-3-methylglutaryl coenzyme A reductase and $280 \%$ increase in $7 \alpha$-hydroxylase activity. Serum cholesterol level is not affected although microsomal cholesterol accumulation and the ratio of hepatic to serum cholesterol increased significantly in the experimental group when compared to the nonchallenged group. Rats exposed to HC-HF diet during lactation alone or during gestation and lactation and then challenged demonstrated enzymatic changes of similar magnitude. Serum and microsomal cholesterol levels also increased significantly by 126 and $150 \%$, respectively. The activity of the HMGCoA reductase system appears to be more sensitive to modulation by diet during gestation than during lactation. However, $7 a-h y-$ droxylase activity is susceptible to dietary manipulation with HICIF diet only during lactation.
\end{abstract}

\section{Speculation}

Low 3-hydroxy-3-methylglutaryl coenzyme A reductase and high cholesterol $7 \alpha$-hydroxylase activities in animals exposed to high cholesterol-high fat diet during gestation and challenged with the same diet at maturity supports the hypothesis that diet during early life influences the regulation of cholesterol homeostasis in adults. Furthermore, our results also suggest that significant alteration of 7 a-hydroxylase activity during lactation. but not during gestation, may be due to late development of the bile acidmetabolizing system during gestation in rats as is known to occur in humans.

Kannel (12) has shown that in adults increased intake of dietary cholesterol is frequently associated with hypercholesterolemia which is one of the major risk factors associated with the incidence of atherosclerosis in humans. It has been suggested that in normocholesterolemic organisms, exposure to dietary cholesterol during early developmental stages initiates biochemical mechanisms that regulate serum cholesterol at lower concentrations later in life (28). These might be the result of early feedhack imprinting on the rate-determining enzymatic steps in cholesterol biosynthesis or degradation.

The effect of dietary cholesterol and other steroids on hiosyn- thesis of cholesterol by liver has been studied extensively. Hepatic cholesterol synthesis is primarily regulated by the activity of 3hydroxy-3-methylglutaryl coenzyme A reductase (HMG-CoA reductase), the rate-determining enzymatic step in cholesterol biosynthesis. Cholesterol $7 a$-hydroxylase, a mixed-function oxidase, catalyzes the rate-limiting step in bile acid biosynthesis from cholesterol $(7,19)$. This enzymatic reaction results in the formation of $7 \alpha$-hydroxycholesterol, which is fully committed to synthesis of bile acids. These two key enzymes of cholesterol metabolism are localized in liver microsomal membranes, and their activities are altered in parallel by cholestramine feeding $(4,32)$. during diurnal rhythm changes $(6,10,20)$, and by adrenalectomy (2. 8). Several investigators have also reported that an increase in $7 a$-hydroxylase is accompanied by a corresponding decrease in the activity of hepatic $\mathrm{HMG}$-CoA reductase after feeding cholesterol-rich diets (4, 21, 25), whereas others have failed to observe any significant changes in cholesterol $7 \alpha$-hydroxylase activity under these conditions $(3,13,23)$. However, to the best of our knowledge, there are no published reports regarding the developmental aspects of cholesterol catabolism by $7 \alpha$-hydroxylase. Systematic and detailed studies of the influence of diet on the rate of synthesis and catabolism of cholesterol at various stages of growth and development are lacking. The present report was designed to study the effects of feeding high cholesterol-high fat $(\mathrm{HC}-\mathrm{HF})$ diets during early stages of growth and development on cholesterol metabolism later in life. The main objective of the present study is to determine whether perinatal exposure to $\mathrm{HC}-\mathrm{HF}$ diet is necessary to establish normal cholesterol homeostasis or whether such exposures have any conditioning effect on the subsequent response to a similar diet in juvenile or adult life.

\section{MATERIALS ANI) METHOIOS}

\section{('HIMIC'AIS}

DI -3-Hydroxy-3-methyl[3-" (")glutaryl (oA (30 $\mathrm{mCi} / \mathrm{mmole})$ was purchased from Amersham Searle Corp., (Arlington Heights,

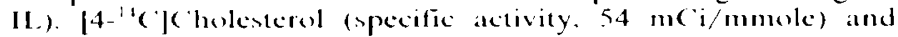
Aquasol scintillation counting fluid were purchased from New England Nuclear (orp., (Boston, MA), Di-HMG-CoA, cholesterol. NADP. glucose-6-phosphate, and glucose-6-phosphate dehydrogenase were purchased from Sigma Chemical ('o.. St. Louis. $\mathrm{MO}$. All the radioactive and cold substrates were purified by thinlayer chromatography. 7a-Hydroxy cholesterol was synthesized by the method described by Shefer and Mosbach (34) from 7 ketocholesterol obtained from Stereloids. Inc. All other chemicals used were of analytical grade.

\section{ANIMAIS ANI) IDIETS}

Sprague-Dawley rats of both sexes (90) to 120 days old) were purchased from Charles River Breeding Laboratories, (Wilmington, MA), and kept for one wh in the animal quarters on regular 
Purina rat chow. Two females were mated with one male each night, and the females were examined for the presence of sperm in the vaginal aspirate each morning. Females with sperm in vaginal aspirates (i.e. pregnant) were separated and randomly assigned to control or $1 "$; cholesterol liquid diet groups according to the following experimental design (Fig. 1).

d) Pregnant rals were divided into two groups. One-half of them were on control diet (group 1). whereas the remaining one-half were on HC-HF diet (group 2) during the period of gestation. After normal delivery. one-half of the mothers in the control group remained on the control diet (group 3 ). whereas the other one-half were switched to the experimental diet (group 4). Similarly, among mothers fed the experimental diet. one-half of them remained on the same diet (group 5), whereas the rest were fed control diet (group 6). At the time of weaning ( 21 days after birth). pups from different mothers within each group were pooled and randomly divided into two groups. One-half of the pups in each group remained on the same diet as their mother, whereas the other one-half were placed either on control or $\mathrm{HC}$ - $\mathrm{HF}$ diet. as shown in Figure 1.

\section{IIITCT OI (IISTATION}

These experiments were designed to study the effects on offspring of exposure of pregnant rats to $\mathrm{HC}-\mathrm{HF}$ diet and challenge with the same diet postweaning. (iroups 7 and 8 served as control. whereas groups 9 and 10 represented intrauterine exposure and subsequent challenge with $\mathrm{HC}-\mathrm{HF}$ diet postweaning.

\section{HFHECT OH LACTATION}

These experiments were designed to study the effects of $\mathrm{HC}$ HF diet given to mothers during lactation and subsequent exposure of offspring to the same diet postweaning on cholesterol metabolism at maturity. Animals were exposed to control diet during gestation. After delivery. pups were suckled by their mothers who were on $\mathrm{HC} \cdot \mathrm{HF}$ diet. Other investigators have clearly demonstrated a significant elevation of cholesterol content of milk when the mothers were fed a $\mathrm{HC}-\mathrm{HF}$ diet (16. 27). Therefore. cholesterol concentration in milk was not measured. Groups 11 and 12 were used to demonstrate the effect of $\mathrm{HC}-\mathrm{HF}$ diet exposure during lactation and maturity.

\section{EFFET OF (IESTATION ANI) IACTATION}

Pregnant rats were exposed to $\mathrm{HC} \mathrm{C}^{\circ}-\mathrm{HF}$ diet both during gestation and lactation periods. At the time of weaning. one-half of the pups were placed on control diet (group 13), whereas the remaining one-half were fed HC-HF diet until the end of the experiments (group 14). These experiments were designed to determine the effect of perinatal exposure to $\mathrm{HC}-\mathrm{HF}$ diet on cholesterol metabolism at maturity.

At the time of maturity (52 days after birth), animals were sacrificed. and blood and liver were collected to assess the effects of maternal exposure to the $\mathrm{HC}-\mathrm{HF}$ diet on $\mathrm{HMG}-\mathrm{CoA}$ reductase, $7 a$-hydroxylase, and microsomal and serum cholesterol accumulation.

DIt: I

The composition of the diet is given in Table 1 . The components of the diet were purchased from Bioserve corp.. and crystalline cholesterol was obtained from Fanning Corp. (holesterol was incorporated in the diet by mechanical blending. Rats were allowed free access to liquid diet in a special feeder from 4:00 PM to 7:(0) AM. Each mother was given $100 \mathrm{ml}$ liquid diet for the lirst 14 days of pregnancy. and then the ration was increased to $150 \mathrm{ml}$ during late gestation and throughout lactation. Newly weaned pups (two in each cage) were given $100 \mathrm{ml}$ for 2 wk after weaning. and then these animals were caged individually and given access

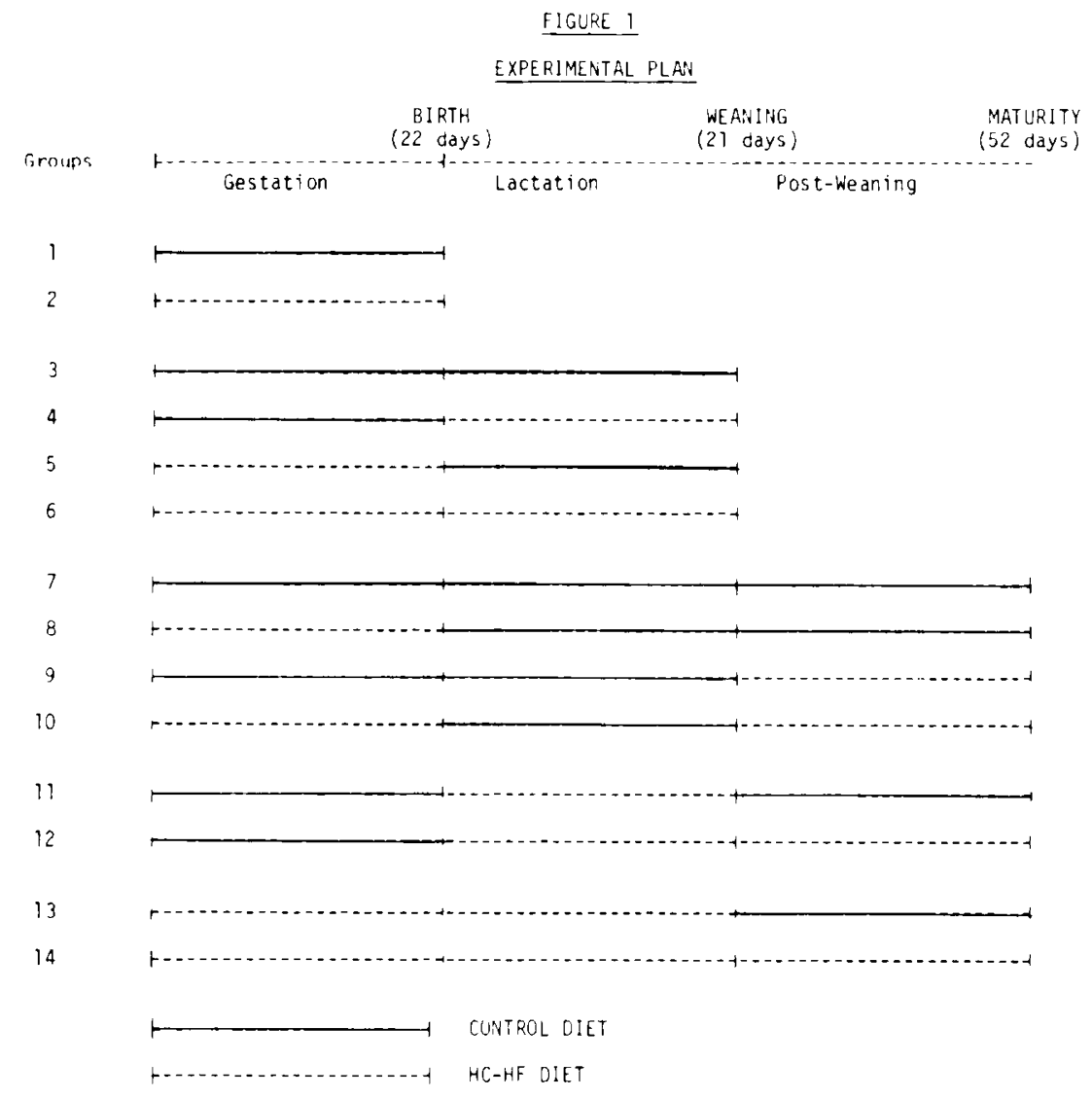

Iig. 1. Dams were fed control or experimental diet during gestation and lactation periods. Pups were weaned on 21 st day after hirth and fed control or experimental diet until the end of the experiment. 
Table 1. Composition of $H C-H F$ liquid diet Ingredients

\section{Protein}

Casein, vitamin-free

1.-Cystine

DI.-Methione

24.5

(). 3

0.2

Carbohydrate

Corn syrup solid

Dextrose (vitamin carrier)

Fats

Corn oil

coconut oil

15.8

31.6

Vitamins:

Mixture

Salts

Hegested salt IV mixture

Manganese sulfate

Potassium sulfate

Zinc carbonate
6.5

0.06

1.96

0.012
${ }^{1}$ Made up to contain one calorie/ml. (One"; (holesterol (USP grade) added in liquid diet by mechanical mixing.

Amount percentage: thiamin $\mathrm{HC}, 19.53$; riboflavin, 0.19 ; pyridoxine. 0.11: pantothenate, 0.78 ; nicotinamide, 0.58 ; choline $(1,29.11$; biotin,

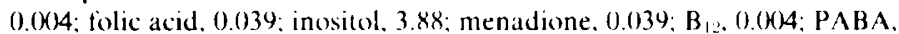
1.94: vitamin A, 0.311; vitamin D, 0.016: vitamin L. 43.48 .

to $100 \mathrm{ml}$ of liquid diet. Animals were always killed between $9: 00$ and 10:00 AM without fasting, and the dark period was from 6:00 PM to 6:00 AM.

\section{PREPARATION OF HEPATIC MICROSOMIS}

The animals were killed by decapitation, and the liver was immediately removed and placed in ice-chilled phosphate buffer saline. Liver was repeatedly washed in phosphate-buffered saline. weighed, minced, and homogenized in cold sucrose. EDTA. and nicotinamide buffer ( $\mathrm{pH} 7.6)$ in a Potter-Elvehjem homogenizer. A $20 \%$ homogenized suspension was centrifuged at $10,000 \times g$ for $20 \mathrm{~min}$ at $4^{\circ} \mathrm{C}$. Microsomes were prepared by ultracentrifugation of the $10,000 \times g$ supernatant at $105,000 \times g$ for $60 \mathrm{~min}$ in cold. The pellet was resuspended in the same buffer containing (0.0) $\mathrm{mM}$ mercaptoethanol. A Tetlon glass homogenizer was used to assist in resuspending the pellet. The resulting homogenate was stored at $-80^{\circ} \mathrm{C}$ for not more than $48 \mathrm{hr}$.

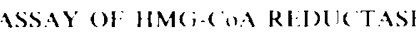

HMG-CoA reductase was measured using a modified procedure of Shapiro et al. (31). The reaction mixture containing $50 \mathrm{mM}$ potassium phosphate ( $\mathrm{pH} 7.4$ ), $30 \mathrm{mM}$ F.DTA, $250 \mathrm{mM} \mathrm{NaC} 1.1$. $\mathrm{mM}$ dithiothritol. $22.5 \mathrm{mM}$ glucose-0-phosphate, $2.25 \mathrm{mM} N A D P$ '. and 3 units of glucose-6-phosphate dehydrogenase in total volume of $160 \mu \mathrm{l}$. Microsomal protein $(0.3 \mathrm{mg})$ was added and preincubated for $5 \mathrm{~min}$. The reaction was initiated with addition of 1.25 $\mathrm{mM}$ 1)1-hydroxymethyl[3-1. C]glutaryl ( oA [HMG-CoA 110.000 $\mathrm{dpm} / \mathrm{nmole})]$ at $37^{\circ} \mathrm{C}$ for $20 \mathrm{~min}$ in a shaker bath. The reaction was terminated by addition of $20 \mu$ of $10 \mathrm{~N} \mathrm{HCl}$. The mixture was incubated at $37^{\circ} \mathrm{C}$ for at least $30 \mathrm{~min}$ to lactonize the mevalonic acid. The precipitated protein was removed by centrifugation, and an aliquot of the supernatant $w$ as applied on $2.5 \mathrm{~cm}$ column of Bio-rex 5. Mevalonic lactone was eluted with $2 \mathrm{ml}$ of distilled water into scintillation counting vial. A denatured blank or a blank without substrate was always included in the assaty system. Under these conditions, the enzyme reaction is linear with time of incubation and protein concentrations. $\mathrm{HMC}-\mathrm{COA}$ reduc- lase activity is expressed as pmoles of $\left[{ }^{14} \mathrm{C}\right]$ mevalonate formed per min per mg of microsomal protein.

\section{ASSAY OF ( HOLESTEROI. 7R-HYDROXYLASI}

Cholesterol 7a-hydroxylase activity was determined at simultaneous intervals with $\mathrm{HMG}-\mathrm{CoA}$ reductase using the method of Shefer et al. (33) with certain modifications. Briefly, $0.05 \mathrm{ml}$ homogenized microsomal suspension in sucrose buffer was incubated with $50 \mathrm{mM}$ phosphate buffer ( $\mathrm{pH} 7.4$ ), $4.5 \mathrm{mM} \mathrm{MgCl.2.3.0}$ mM NADP, $2.5 \mathrm{mM}$ glucose-6-phosphate, and 2 units of glucose6-phosphate dehydrogenase in a total volume of $0.85 \mathrm{ml}$. The reaction was initiated by addition of $0.1 \mathrm{ml}$ cholesterol substrate. containing cholesterol (10.000 dpm/nmole). The cholesterol substrate was prepared by adding thin-layer chromatography-purified cold and $\left.\right|^{1 .} \mathrm{C}$ )cholesterol in acetone-containing cutscum. The content was evaporated under nitrogen and mixed thoroughly on a Vortex in homogenizing buffer. The reaction was carried out at $37^{\circ} \mathrm{C}$ for $20 \mathrm{~min}$ in dark in a shaking bath. After completion of incubation. reaction was terminated by adding $7 \mathrm{ml}$ of $1: 5$ ethanol: methylene chloride mixture. Solvent layer was removed after thorough mixing on Vortex. The pellet was again extracted, and the pooled solvent fraction was evaporated under nitrogen. The residue was dissolved in an adequate amount of isopropanol and applied on thin-layer silica gel $G$ plate (Eastman Chromogram Sheets) with authentic standards. The chromatogram was developed in an ethyl acetate, benzene, and ether $(1: 1: 2)$ solvent system at room temperature in dark. The spot was developed by spraying $3.5 \%$ phosphomolybdic acid. and the $7 \alpha$-hydroxycholesterol spot was cut and counted. In each experiment, blanks made either by inactivating the reaction with methylene chloride or boiling the microsomes were substracted from the results. The amount of endogenous hepatic cholesterol was also included as total cholesterol pool in calculating the specific activity of the cholesterol substrate. Cholesterol $7 \alpha$-hydroxylase activity is expressed as the pmoles of $7 \alpha$-hydroxylase formed per min per $\mathrm{mg}$ of microsomal protein.

\section{MICROSOMAI ANI) SIRIIM (HOILSTEROI. DETTERMINATION}

Total cholesterol in hepatic microsomes was extracted with chloroform:methanol $(2: 1)(\mathrm{v} / \mathrm{v})$ and determined by the method described by Mitropoulos e't al. (22). Serum cholesterol level was measured by the procedure of Allain et al. (1). Microsomal protein was measured by the standard method of Lowry et al. (17).

\section{RESUITS}

HFE(T OF: INTR AUTLRINI EXPOSI!RE: TO H(-HF IOIIT AND

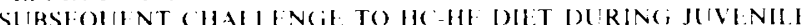
PIRI()I)

Experiments were designed to test the thesis that prenatal exposure to $\mathrm{HC}-\mathrm{HF}$ diet leads to more effective control on cholesterol homeostasis in later life. The prenatal exposure of pups to maternal HC-HF diet and subsequent challenge with the same diet during the postweaning period resulted in highly significant results (lable 2). When the mothers were ted the experimental diet during gestation and then not challenged during the postweaning period. there was no effect on enzyme activity. microsomal. or serum cholesterol level (Table 2. group 7 versus 8). In a similar experiment, but with the addition of the experimental diet during the postweaning period (Table 2, group 9 v'ersus 10). the results were highly significant. HMG-C 'oA reductase activity declined by more than 76\%.7a-hydroxylase was induced by almost two-fold, and there was increased accumulation of microsomal and serum cholesterol. although the ratio of hepatic to serum cholesterol was not affected. This series of experiments clearly indicates that gestational exposure to $\mathrm{HC}-\mathrm{HF}^{-}$diet markedly changes the activity of HMC $-C^{\circ}$ oA reductase and $7 a-h y d r o x-$ ylase upon subsequent exposure to the same $\mathrm{HC}^{\prime}-\mathrm{HF}^{\prime}$ diet in adulthood. 
EFFECT OF HC-HF DIET DULING SUCKI.ING ON CHOLESTEROL METABOI.ISM

Inasmuch as human studies have shown that breast-fed infants had low levels of serum cholesterol in adulthood in spite of a high cholesterol diet. these experiments were undertaken to test the effect of maternal HC-HF diet during lactation on cholesterol metabolism in the offspring at later life. In this experiment. pups were suckled by mothers on HC-HF diet (Table 3, groups 11 and 12) and later challenged with the same diet during the postweaning period. Prolonged exposure to $\mathrm{HC}-\mathrm{HF}$ diet during the lactation and postweaning period had a pronounced effect on enzyme activities (Table 3, group II versus 12). HMG-CoA reductase activity of the challenged group declined by more than $52 \%$ from the nonchallenged group: $7 \alpha$-hydroxylase activity increased by almost three-fold. No change in serum cholesterol level has been observed. although microsomal cholesterol accumulation increased significantly in group 12 when compared to group 11. The ratio of hepatic to serum cholesterol in group 12 increased significantly compared to group 11 (Table 3 ). By comparison (Table 3 ), animals that were not exposed to $\mathrm{HC}-\mathrm{HF}$ diet during lactation (group 9) but exposed to HC-HF diet post-weaning as in group 12. show significant alteration in all the parameters of cholesterol metabolism except for its serum value when compared with controls (group 9). Again, it appears that prior exposure to $\mathrm{HC}-\mathrm{HF}$ diet is associated with altered levels of enzyme activity.
EXPOSURE TO HC.HF DIET DURING (IESTATION. LACTATION AND) POSTWEANINi;

Table 4 shows the effect of $\mathrm{HC} \cdot \mathrm{HF}$ diet during gestation and lactation. One group of animals received $\mathrm{HC}-\mathrm{HF}$ diet (Table 4. group 14). whereas the other group was changed to control diet post-weaning (Table 4. group 13). All the parameters of cholesterol metabolism are significantly altered. HMG-CoA reductase activity declined by almost $60 \%$. whereas cholesterol $7 \alpha$-hydroxylase activity stimulated by more than $270 \%$. Microsomal and serum cholesterol levels also increased significantly, along with an increase in the ratio of microsomal cholesterol to that of serum cholesterol level. When groups 7 and 13 were compared, enzyme activities showed the same trend, although the animals had been on the control diet for 31 days during the postweaning period (Table 4, group 13).

COMPARISON OF FEIIDIN( ; HC -HF DIET ON (HOLESTEROL. METABOLISM DURING (IESTATION. LACTATION, AND CHAI.IINC DURIN(; JUVENILE PERIOL)

The sensitivity of the cholesterol-metabolizing system to dietary alterations was investigated by comparing the effects of $\mathrm{HC}^{\circ}-\mathrm{HF}$ diet fed during gestation to that fed during lactation and the subsequent responses to challenge by the same diet (Table 5). Animals were exposed to $\mathrm{HC}-\mathrm{HF}$ diet during the juvenile period. The activity of the HMG-CoA reductase system appears to be

Table 2. Effect of HC-HF diet during gestation on cholesterol metabolism in adult rats

\begin{tabular}{|c|c|c|c|c|c|c|}
\hline $\begin{array}{l}\text { Group } \\
\text { (Fig. 1) }\end{array}$ & Treatment & $\begin{array}{c}\text { HMG-CoA reductase } \\
\text { (pmoles mevalonate/ } \\
\mathrm{min} / \mathrm{mg} \text { protein) }\end{array}$ & $\begin{array}{c}7 \alpha \text {-hydroxylase } \\
\text { (pmoles } 7 \alpha \text {-hydroxy- } \\
\text { cholesterol/min } \\
\mathrm{mg} / \text { protein) }\end{array}$ & $\begin{array}{l}\text { Microsomal } \\
\text { cholesterol } \\
\text { ( } \mu \mathrm{g} \text { protein) }\end{array}$ & $\begin{array}{c}\text { Serum } \\
\text { cholesterol } \\
(\mathrm{mg} / \mathrm{dl})\end{array}$ & $\begin{array}{c}\text { Ratio of hepatic } \\
\text { and serum } \\
\text { cholesterol }\end{array}$ \\
\hline 7 & Cont $^{2.3}-$ Cont $^{4}-$ Cont $^{5}(15)^{4}$ & $252.3 \pm 28.39^{i}$ & $6.02 \pm 1.02$ & $27.3 \pm 4.78$ & $68.9 \pm 2.80$ & $0.396 \pm 0.02$ \\
\hline 8 & Expt-Cont-Cont (7) & $190.5 \pm 19.62$ & $7.65 \pm 0.55$ & $23.3 \pm 1.28^{\wedge}$ & $63.7 \pm 6.99$ & $0.352 \pm 0.05$ \\
\hline 9 & Cont-Cont-Expt (7) & $174.1 \pm 16.75$ & $10.76 \pm 0.91^{\times}$ & $25.6 \pm 3.77$ & $72.5 \pm 6.96$ & $0.403 \pm 0.02$ \\
\hline 10 & Expt-Cont-Expt $(7)^{4}$ & $41.5 \pm 3.24^{\kappa}$ & $19.82 \pm 1.48^{\times}$ & $31.5 \pm 2.72^{\star}$ & $92.2 \pm 8.88^{\mu}$ & $0.365 \pm 0.05$ \\
\hline
\end{tabular}

'Pregnant rats were fed either control or experimental diet throughout the period of gestation. The animals switched to control diet after delivery throughout the lactation period. After weaning, pups were given either control or experimental diet as indicated. Microsomal preparations from the livers of rats killed at 52 days of age were assayed for HMG-CoA reductase, $7 \alpha$-hydroxylase, and microsomal cholesterol accumulation. Serum was collected at the time of killing for serum cholesterol level as described in "Materials and Methods."

'Cont, control diet; Expt, experimental diet.

${ }^{3}$ Gestation

$\checkmark$ Lactation.

"Postweaning.

"Numbers in parentheses. number of animals.

Mean \pm S.E.

${ }^{*} P$ is significant at least at $<0.025$ from control group 7 .

${ }^{9} P$ is significant at least at $<0.025$ from nonchallenged group 9. except hepatic and serum cholesterol ratio.

Table 3. Effect of HC-HF diet during lactation on cholesterol metabolism in adult rats

\begin{tabular}{|c|c|c|c|c|c|c|}
\hline $\begin{array}{l}\text { Group } \\
\text { (Fig. 1) }\end{array}$ & Treatment & $\begin{array}{l}\text { HMG-CoA reductase } \\
\text { (pmoles mevalonate } \\
\mathrm{min} / \mathrm{mg} \text { protein) }\end{array}$ & $\begin{array}{c}7 \alpha \text {-hydroxylase } \\
\text { (pmoles } 7 a-h y d r o x y- \\
\text { cholesterol/min/ } \\
\text { mg protein) }\end{array}$ & $\begin{array}{l}\text { Microsomal } \\
\text { cholesterol } \\
\text { ( } \mu \mathrm{g} / \mathrm{mg} \text { micro- } \\
\text { somal protein) }\end{array}$ & $\begin{array}{c}\text { Serum } \\
\text { cholesterol } \\
\text { (mg/dl) }\end{array}$ & $\begin{array}{c}\text { Ratio of hepatio } \\
\text { and serum } \\
\text { cholestero! }\end{array}$ \\
\hline 7 & $\operatorname{Cont}^{2 \cdot 3}-\operatorname{Cont}^{4}-\operatorname{Cont}^{5}$ & $252.3 \pm 28.39^{\prime \prime}$ & $6.02 \pm 1.02$ & $27.3 \pm 4.78$ & $68.9 \pm 2.80$ & $0.396 \pm 0.02$ \\
\hline 9 & Cont-Cont-Expt & $174.1 \pm 16.75$ & $10.76 \pm 0.91$ & $25.6 \pm 3.77$ & $72.5 \pm 6.96$ & $0.353 \pm 0.05$ \\
\hline 11 & Cont-Expt-Cont & $227.0 \pm 37.78$ & $8.69 \pm 0.38$ & $27.4 \pm 0.91$ & $73.7 \pm 4.72$ & $0.372 \pm 0.02$ \\
\hline 12 & Cont-Expt-Expt ${ }^{N}$ & $107.7 \pm 13.29^{\circ}$ & $24.47 \pm 1.11^{7}$ & $41.6 \pm 2.10^{\circ}$ & $81.9 \pm 3.20^{\circ}$ & $0.508 \pm 0.03$ \\
\hline
\end{tabular}

1 Animals were fed control diet during pregnancy. (iroups 7 and 9 remained on control diet during lactation. whereas groups 11 and 12 were transferred to experimental diet. After weaning. animals in groups 9 and 11 were again transferred to experimental or control diets, respectively. Conditions are the same as described in Table 2. Each value represents the data from seven animals in each group, except for group 7 comprising fifteen animals.

2 Cont, control diet: Expt, experimental diet.

Gestation.

4 Lactation

¿Postweaning

"Mean \pm S.E.

$P$ significant at least $<0.01$ from group 7 .

${ }^{*} P$ significant at least $<0.01$, except serum cholesterol level from group 11 and $<0.01$ from group 9. 
more sensitive to modulation by diet during gestation than during lactation. In contrast, $7 \alpha$-hydroxylase activity is susceptible to dietary manipulation with $\mathrm{HC}-\mathrm{HF}$ diet only during the period of lactation. Microsomal cholesterol accumulation also seems to be more sensitive to dietary alteration during lactation. However, no effect on serum cholesterol level has been observed in these two groups (Table 5).

\section{DISCUSSION}

Experiments with animals have shown that diet at an early age may have an important influence on the regulation of cholesterol homeostasis in later life. Data on the effect of nutrition during gestation on cholesterol metabolism of the offspring is limited. Rudis et al. (29) have reported very low serum cholesterol levels in rats when $\mathrm{HC}-\mathrm{HF}$ diets were fed to their mothers during gestation and lactation and when they were subsequently challenged with the same diet during adulthood. Attempts to study the effect of lactation on serum cholesterol levels at maturity are numerous. Hahn and Koldovsky (9) reported that female rats weaned prematurely have levels of serum cholesterol about $50 \%$ higher than those rats weaned at the usual time and then challenged with high-cholesterol diet in adulthood. Kris and Frantz. (15) reported that pups taken from mother at birth and fed low or chfolesterol-free milk for 21 days have $40 \%$ higher serum cholesterol levels when challenged with $0.5 \%$ cholesterol diet at maturity (5I days of age). Reiser (26) reported that cholesterol in the milk of sucklings influences the development of enzymes concerned with serum cholesterol homeostasis in the adult. The influence of diets on cholesterol anabolic or catabolic enzyme development has been studied but not extensively $(5,11,14,18)$. Recently. Ness et al. (24) have observed the developmental pattern of HMG-CoA reductase in lung. liver, and brain of rats and have reported that liver reductase activity varied in a reciprocal fashion with serum cholesterol levels.

In the present study, the complex developmental pattern of cholesterol metabolism in the rat appears to be related to dietary factors. Most important is the time of exposure during various stages of growth and development. Exposure to $\mathrm{HC}-\mathrm{HF}$ diet at any state of development alters the cholesterol metabolism significantly. However. prenatal exposure with $\mathrm{HC} \cdot \mathrm{HF}$ diet and challenge with the same diet postweaning resulted in the greatest inhibition of $\mathrm{HMG}-\mathrm{COA}$ reductase at maturity and consequently low serum cholesterol level in adulthood. In this study, serum cholesterol level in the challenged group is significantly higher than in those not exposed to the HC-HF diet during gestation (Table 2, group 9 versus 10 ). We cannot rule out the possibility that serum cholesterol level in the challenged group (Table 2 . group 10) might have decreased when the animal reached adulthood as has been reported by Kris and Frantz (15).

Animals fed HC-HF diet by their mothers during lactation and receiving continued exposure to the same diet after weaning show more alteration in cholesterol $7 \alpha$-hydroxylase than in HMG-CoA reductase (Table 3, group 12: Table 5). Animals suckled on low-

Table 4. Effect of HC-HF diet hoth during gestation and lactation on cholesterol metabolism in rats ${ }^{1}$

\begin{tabular}{|c|c|c|c|c|c|c|}
\hline $\begin{array}{l}\text { (iroup } \\
\text { (lig. l) }\end{array}$ & Treatment & $\begin{array}{l}\text { IIMCj-CoA reductase } \\
\text { (pmoles mevalonate/ } \\
\text { min/mg protein) }\end{array}$ & $\begin{array}{l}\text { 7a-Hydroxylase } \\
\text { (pmoles 7a-hydroxy- } \\
\text { cholesterol/min/ } \\
\text { mg protein) }\end{array}$ & $\begin{array}{l}\text { Microsomal } \\
\text { cholesterol } \\
\text { ( } \mu \mathrm{g} / \mathrm{mg} \text { micro- } \\
\text { somal protein) }\end{array}$ & $\begin{array}{l}\text { Serum } \\
\text { cholesterol } \\
(\mathrm{mg} / \mathrm{dl})\end{array}$ & $\begin{array}{l}\text { Ratio of hepatic } \\
\text { and serum } \\
\text { cholesterol }\end{array}$ \\
\hline 7 & $C^{\prime}$ ont $t^{2}-C^{\prime}$ ont $-C^{\prime}$ ont' $(15)^{\prime \prime}$ & $252.3 \pm 28.39^{\circ}$ & $6.02 \pm 1.02$ & $27.3 \pm 4.78$ & $68.9 \pm 2.80$ & $0.396 \pm 0.02$ \\
\hline 13 & Expt-Expt-Cont (17) & $136.0 \pm 8.71^{x}$ & $8.74 \pm 0.75^{4}$ & $26.1 \pm 1.41$ & $75.5 \pm 4.42$ & $0.360 \pm 0.02$ \\
\hline 14 & Expt-Lxpt-Expt $(14)^{\prime \prime}$ & $54.2 \pm 4.69^{x}$ & $23.69 \pm 2.65^{\mu}$ & $39.5 \pm 2.16^{\mathrm{N}}$ & $94.3 \pm 7.09^{*}$ & $0.450 \pm 0.03^{\kappa}$ \\
\hline
\end{tabular}

Animals were exposed to $H(-11)^{*}$ diet during gestation and lactation. whereas the animals in group 7 were exposed to control diet throughout the periods of growth and development. Animals in group 13 were transferred to the control diet after weaning, whereas rats in group 14 remained in 13 111: diet until the end of the experiment. Details are the same as described in Table 2 . Only $7 \alpha$-hydroxylase shows a significant correlation with microsomal cholesterol accumulation (group 13. $F=0.81 ; P<0.01$ ): group $14, F=0.63 ; P<0.01$.

- cont. control diet: Expt. experimental diet.

Gestation.

'Iactation.

"Postweaning.

"Numbers in parentheses, number of animals.

Mean \pm S.E.

${ }^{\mathrm{N}} P$ is significant at least at $<0.05$ from control group $?$

" $P$ is significant at least at $<0.05$ between groups 13 and 14 .

Table 5. Comparative effect of $H C-H F$ diet introduced during gestation or lactation and challenge with HC-HF diet postweaning in cholesterol metabolism in rats ${ }^{1}$

\begin{tabular}{|c|c|c|c|c|}
\hline $\begin{array}{l}\text { ('holesterol } \\
\text { parameters }\end{array}$ & 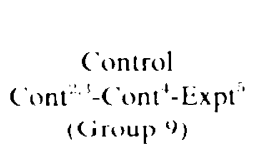 & $\begin{array}{l}\text { Cxpt iestation } \\
\text { ("i cont - Expt } \\
\text { (ciroup } 10)\end{array}$ & $\begin{array}{l}\text { Lactation } \\
\text { Cont'-Expt -Expt" } \\
\text { ("i control) } \\
\text { (ciroup 12) }\end{array}$ & $\begin{array}{c}P \text { between gestation } \\
\text { and lactation } \\
\text { groups }\end{array}$ \\
\hline Cos reductase & $1(k) \pm 9.62^{4}$ & $23.8 \pm 1.86$ & $61.1 \pm 7.60$ & $<0.025$ \\
\hline droxylase & $100 \pm 8.45$ & $184.2 \pm 13.75$ & $227.4 \pm 10.32$ & $<0.05$ \\
\hline omal cholesterol & $100) \pm 14.72$ & $123.1 \pm 10.63$ & $162.5 \pm 8.20$ & $<0.05$ \\
\hline cholesterol & $100 \pm 1.32$ & $127.2 \pm 12.25$ & $113.0 \pm 4.42$ & N.S. \\
\hline
\end{tabular}

Serum cholesterol

$127.2 \pm 12.25$

' Animals were fed HC-HF diet either during gestation or lactation. After weaning, all the groups were exposed to HC-HF diet until the end of the experiment. Conditions are the same as described in Table 4 . The control values are: IIMG-CoA reductase. $174.1 \pm 16.75$ pmoles mevalonate per min per mg microsomal protein: $7 a$-hydroxylase. $10.76 \pm 0.91$ pmoles $7 a$-hydroxy cholesterol per min per mg microsomal protein: microsomal cholesterol. $25.6 \pm 3.77 \mu \mathrm{g} / \mathrm{mg}$ microsomal protein: and serum cholesterol level. $72.5 \pm 0.96 \mathrm{mg} / \mathrm{d}$.

Cont, control diet: Expt, experimental diet.

'Gestation.

'Lactation.

"Postweaning.

"Mean \pm S.L. of 7 animals. 
cholesterol milk would, therefore. have high cholesterol and low bile acid synthesis, resulting in high serum cholesterol concentrations. This phenomenon could imprint on cholesterol metabolism during early developmental periods and control the cholesterol homeostasis in adulthood. In human studies, it has been reported that primitive people who breast fed their children for two to three years had low levels of serum cholesterol and low incidence of atherosclerosis during adulthood. despite a diet high in cholesterol content (30). On the other hand. in advanced societies. children are seldom breast fed and are frequently weaned at early ages to milk formula. lower in fat and cholesterol content than breast milk. In these cases. levels of serum cholesterol and incidence of cardiovascular disease are higher in adults (36).

Exposure to HC-HF diets during gestation and lactation periods shows that the diets fed during perinatal periods may have important and long-lasting effects on enzymes in rats, even when the HC $-\mathrm{HF}$ diet has not been fed after 21 days of age (Table 3, group 7 versus 9). Significant alteration of 7 a-hydroxylase activity during lactation, but not during gestation, suggests that $7 a$-hydroxylase system of bile acid metabolism develops late during gestation in rats as is known to occur in humans (37).

Takeuchi et al. (35) have reported impairment in the distribution of cholesterol to the liver from peripheral circulation in good responder rats when fed cholesterol orally. This effect in hypercholesterolemic rats correlates well with high serum cholesterol. low cholesterol 7 a-hydroxylase activity. and diminished bile acid synthesis and excretion when compared to the normocholesterolemic rats. In the present experiments. animals exposed to HC$\mathrm{HF}$ diet during gestation and challenged with the same diet postweaning showed no change in cholesterol transport from serum to liver. Thus, gestational cholesterol $7 \alpha$-hydroxylase activity is not altered to the same degree as during lactation (Table 5). Animals exposed to $\mathrm{HC}-\mathrm{HF}$ diet during lactation and postweaning showed a highly significant increase in cholesterol $7 \alpha$-hydroxylase activity, along with an active cholesterol transport into the liver from serum. Similarly, when animals were exposed to $\mathrm{HC}-\mathrm{HF}$ diel during gestation and lactation and then challenged with the same diet postweaning. they showed similar results. Exposure during gestation showed the same effects to a lesser extent than observed during lactation (Tables 4 and 5). However, serum concentrations of cholesterol in this study remained elevated as a result of the continuous exposure to large amounts of cholesterol.

\section{RHILRIN('S ANI) NOTHS}

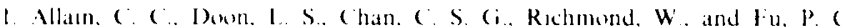
linsmatic determunation of total serum cholesterol. (lin. (chem. 2t) 470 19741.

2. Balasubramantam. S. Mitropoules. K. A. and Mant. N. B. Hormonal control

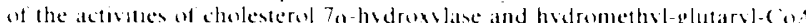
reductase in rats In: S. Matern. J. Hatchenschmidt. P. Bach. W. Cierok Advances in Bile Acid Research. III. Bile Acid Meeting Freshurg Br. p. ol (1) K. Sihattaner-Verlatg. Sttutgart. 1975.

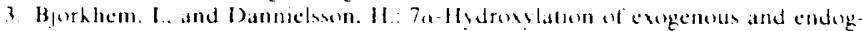

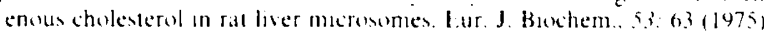

4. Burd. (i. S. Siholan. N A. and Matton. J R. Faturs intluencing cholesterel

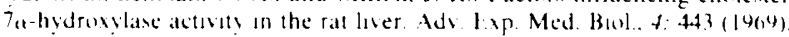

S. Calandra. S. Quartaroli. ( $i$. S . and Montaguts. M Iffect of cholesterol feeding on cholesterol housunthess in maternal and foetal rat liver. Lur. J. ( hin. Invest. 5: $27(1475)$

6. Dannielson. H: Relatwonshep hetween diurnal variations in hosunthesis of cholesterel and hile atcds. Sterouds. 20, $0.3(1972)$

7. Dannelswon. H. Ernarson. $K$. and Johnson. (i.: Iffect of hilary drainage on individual reactions in the conversion of cholesterel to taurocholic acid tur J. Biochem. ? $44(1967)$

x. Lduards. P. A Afect of adrenalectoms and hypephesectems on the circadian

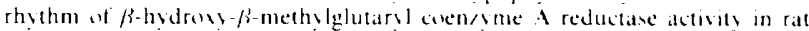
liver J Bul (hem. 245: $2912(197,31$

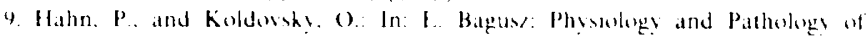

Adaption Mechanisnss p. 48 (Pergman Press, Oxford, England. I969).

10. Kandutsch, A. A.. and Satucjer, S. B... Prevention of cyclic and triton-induced increasen in hydromethylglutaryl coenzyme A rejuctase and sterol synthesis hy puromycin. J. Biol. (hem.. 244: 2299 (1969).

11. Kandutsch. A. A. and Saucier, S. F.: Regulation of sterol synthesis in developing brains of normal and Jimpy mice. Arch. Biochem. Biophys. 1.35: 201 (1969)

12. Kannel. W. B.: Lipid profile and potential coronary victim. Am. J. ('lin. Nutr. 24: $11074(1971)$.

13. Kim. () N. Rogers, D. H. L., J. R., Remer. J. M.. I.ee. K. T. and Thomas, W A.: Fffects of cholestyramine on cholesterol halance parameters and hepatic HM( $;$ - (ind reductase and cholesterol $7 a$-hydroxylase activities in swine. Fxp. Mol. Pathol.. 26: 434 (1977)

14. Kowanen. P. T. Goldsein. J. I... and Brown. M. S.: High levels of 3-hydroxy-3methylglutaryl coensme A reductase activity and cholesterol synthesis in the wary of pregnant rabbit. J. Bow (hem.. 253: 5126 (1978)

15. Kris. P. M., and Frantz. I. D. . Jr.: The influence of early nutrition on the serum cholesterel of the adult rat. Fed. Proc.. if: $760(1978)$.

16. Kris. P. M. Layman. D. K. York. P. V.. and Frant. I. D.. Jr.: The influence of early nutrition on the serum chotesterol of the adult rat. J. Nutr.. 10\%: 980 $(1974)$.

17. L.owry, D). H., Ronenhrough, N. J., Farr, A. 1... and Randall. R. J.: Protein measurement with folm phenol reagent. J. Bol. (hem.. 193: 265 (1951).

18. MoNamara. 1). J.. Quatchenhush. F. W. and Rodwell. V. W.: Regulation of hepatic 3-hodroxv-3-methvlglutaryl coenswe A reductase: developmental pattern. J. Bul (hem. of 5805 (19972)

19. Mitropoulon. K. A. and Balasubramaniam. S.: (holesterol 7 a-bydroxvlase in rat liver microsomal preparations. Buchem. J., Lix: I (1972)

20. Mitropoulon. K. A.. Subramaniam. S. (ihbhons. (;. F... and Reeves. L. R.. Diurnal variaton in the activity of cholesterol 7a-hydroxylase in the lisers of fed and listed rats. FHBS I.ett., 2?: 203 (19)72)

21. Mitropoulos. K. A.. Subramantam. S. and Myant. N. B.: The effect of interruption of the entero-hepatic circulation of bile acids and of cholesterol feeding on cholesterol 7 a-hydroxylase in relation to the diurnal rhythm in its activity. Biochim. Bouphys Acta. 320: $42 \times(1973)$.

22. Mitropoulos. K. A. Venkatesen, S., Balasubramanian, S.. and Peters. T.: The submicrosomal localization of 3 -hvdroxy-3-methylglutaryl-coen/yme A reductase, cholesterol 7a-hydroxvlase and cholesterol in rat liver. Eur. J. Binchem.. $x: 419(1978)$.

23. Mosbach. H. H.: Regulation of hile acid in synthess. In: P. Back. V. (ierok: Bile Acids in Human Diseases. II Bile Acid Meeting. Freihurg i. Br. p. ky (f. K Schattaser Verlag. Stuttgart. 1972)

24. Ness. (i. ( . Miller. J. P.. Moftler M. H. Wouds 1. S. and Harris. H. B Perinatal development of 3 -hydroxy-3-methylglutaryl coensyme a reductase activity in rat lung. liver and bratin. 1.ipids. $14: 447$ (1979).

25. Raticht, K. F. Cohen, B. I. Sheter, S. and Mushach. I. H. Sterol balance studies in the ratt. Eftects of detary cholesterol and $\beta$-sitosterol on sterol balance and rate-limiting ensymes of sterol metaholism. Biochim. Biophys. Actat 365: 379 (1975).

26. Reiser. R.: Control of adult serum cholesterol by the nutrition of the suckling. (irculation. 2/4: $3(197)$.

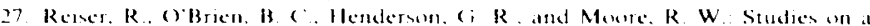
powshle function for cholesterol in milh. Nutr. Rep. Int. 19: 835 (1979).

2x Reser. R. and Sidelman. 7... (iontrol of serum cholesterol homeostass by cholesterol in the milk of the suckling rat. J. Nutr.. /1)?: I(K)y (I472)

29. Rudis. B. Marktl. W.. and Widham. K.: Effects of a high fat and cholesterol diet of pregnant and lactating rats on the liped metabolism of their offspring. I International congress of Nutrition. p. 179 (Ahstratct 3318$)(1475)$

31). Shacter. (): When the eshimo comen wo lown. Nutr. Today. o: 8 (1971)

31. Shapiro, D) J.. Imblum. R. 1... and Roducll. V. W.: Thon laver chromatographic assaty for HM(;-Cind reductase and mevalenic acid Anal. Binchem. $31 \cdot 3 \times 3$ (latig).

32. Shefer. S. Hauser. S. and Monbach, 1... 7a-llydroxylation of cholesterol hy rat liver microsomes. J. I.ipid Res. 10:42 11975 )

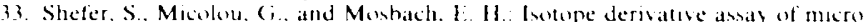
somal choleserel 7a-hydroxylates. J. I.ipid Res.. 1):328 (1968)

34. Shefer. S.. and Moshach. 1 . H.: (personal communication)

35. Takeuchi. N., Ite. M. and Yamanura. Y.: (hulesterol metabolism in rats sensitue a high cholesterol dee Ads lap. Biol. Med. 07: 267 (1476)

36. Walker. A. R. P.: Overueight and hypertension in emerging population. Am lleart J.. Ox: $51 \times(1404)$

37. Watkins. J. B. Ingall. D., Scerepantk. P.. Klem. P. D). and I.ester. R.: Bile salt metabolism in the newhorn. measurement of pool ste and it nthess by stable isotope technique. N. Fingl. J. Med.. 2.6.5: 431 (197.3)

38. Requests for reprints should be addressed (w: Dr. Syed M. Nas eem. Dowsolun of Adelescent Medicine. Department of Pedatrics. (Inicersty of Maryland School of Medicine. Baltimore. MI) $212(12$ (ISA)

39. Thes research was supporled by Nllf (irant NS-1167749

411. Received for publication July i6. 1974.

41. Accepted for publication January 2. losil. 